\title{
Educación para el Desarrollo en los Programas Uni- versitarios para Mayores (PUM) en España
}

\section{Miguel Ángel Martínez Martínez', Antonio Caballer Miedes²}

Resumen: En las últimas décadas, los Programas Universitarios para Mayores (PUM) han experimentado un importante desarrollo y crecimiento en España como respuesta a los cambios socio-demográficos acaecidos en nuestro país, en consonancia con la perspectiva de Aprendizaje a lo Largo de la Vida (ALV) incorporada en la Agenda 2030.

A través de una revisión sistemática de la bibliografía, el presente estudio intenta analizar hasta qué punto los PUM incorporan estrategias de Educación para el Desarrollo (EpD), como herramienta en la construcción de una ciudadanía activa entre las personas mayores que asisten a los PUM.

Tras la revisión, podemos afirmar que los PUM incorporan muchos de los objetivos e ideas planteadas desde la EpD pero no desde una estrategia global. Por tanto, se considera necesario profundizar en la investigación acerca de la EpD en estos programas, tanto por parte de las Universidades como de los profesionales de la EpD.

Palabras clave: Educación para el Desarrollo, Programas Universitarios para Mayores, Aprendizaje a lo Largo de la Vida.

Fecha de recepción: 8 de febrero de 2019.

Fecha de admisión definitiva: 6 de noviembre de 2019.

\footnotetext{
1 Universitat Jaume I de Castelló. Máster en Cooperación al Desarrollo - Estudiante de Doctorado.

${ }^{2}$ Universitat Jaume I de Castelló. Doctor en Psicología - Profesor Titular.
} 


\section{Development education in university programmes for adults in Spain}

Abstract: In line with the lifelong learning perspective incorporated in the Agenda 2030, in recent decades university programmes for adults have undergone significant development and growth in Spain, and have come as a response to socio-demographic changes that have affected our country.

By means of a systematic literature review, this study attempts to analyse the extent to which university programmes for adults incorporate strategies for developmenteducation as a tool in the building of an active citizenry among adults who attend such programmes.

After the review, we can affirm that these programmes incorporate many of the objectives and ideas put forward by development education but not in the form of a global strategy. It is, therefore, deemed necessary to widen the research into development education as part of these programmes, both by Universities and professionals.

Key words: Development Education, University Programmes for Adults, Lifelong Learning.

\section{Éducation au développement dans les programmes universitaires pour adultes en Espagne}

Résumé: Au cours des dernières décennies, les programmes universitaires pour adultes ont connu un développement et une croissance importants en Espagne, conformément à la perspective de l'apprentissage tout au long de la vie incorporée dans l'Agenda 2030 , et sont venus en réponse aux changements sociodémographiques qui ont affecté notre pays.

Au moyen d'une revue systématique de la littérature, cette étude tente d'analyser dans quelle mesure les programmes universitaires pour adultes intègrent des stratégies d'éducation au développement comme outil dans la construction d'une citoyenneté active chez les adultes qui suivent ces programmes.

Après l'examen, nous pouvons affirmer que ces programmes intègrent bon nombre des objectifs et des idées avancés par l'éducation pour le développement, mais pas dans une stratégie globale. II est donc consideré nécessaire $d$ 'amplifier la recherche en éducation pour le développement dans ces programmes, tant par les universités que par les professionnels.

Mots clé: Éducation au développement, programmes universitaires pour adultes, apprentissage tout au long de la vie.

\section{Introducción}

Es indudable que los cambios sociodemográficos que están sufriendo, especialmente los países occidentales, unidos a los socioeconómicos, hace necesario un replanteamiento, ya iniciado en las últimas décadas, de la concepción que se tiene con respecto al envejecimiento y el papel que los centros de enseñanza superior, a través de los Programas Universitarios de Mayores (PUM) han de tener en la consecución del mismo de manera activa a través de sus tres funciones tradicio- 
nales: la docente, la investigadora y la de extensión universitaria; y la última en incorporarse, el aprendizaje a lo largo de la vida (ALV), desde una estrategia de Educación para el Desarrollo, como principales herramientas para, por una parte, el cambio necesario en nuestras sociedades y por otra, para considerar a nuestros mayores como agentes activos de dicho cambio.

Centrándonos en los cambios sociodemográficos, la Organización de Naciones Unidas (ONU), en su última prospección sobre población mundial (ONU, 2017), plantea un aumento de la esperanza de vida a nivel de la población española para el año 2030 de 1,4 años en relación con el año 2015 y estableciendo la esperanza de vida en 84,8 años (Figura 1), lo cual, según datos del mismo informe, sitúa a España entre los cinco países con mayor esperanza de vida del mundo para el 2030 y con 87,3 años para el 2050 entre los tres primeros junto China y Japón.

\section{FIGURA I. Esperanza de vida en España en el periodo 1990-2050}

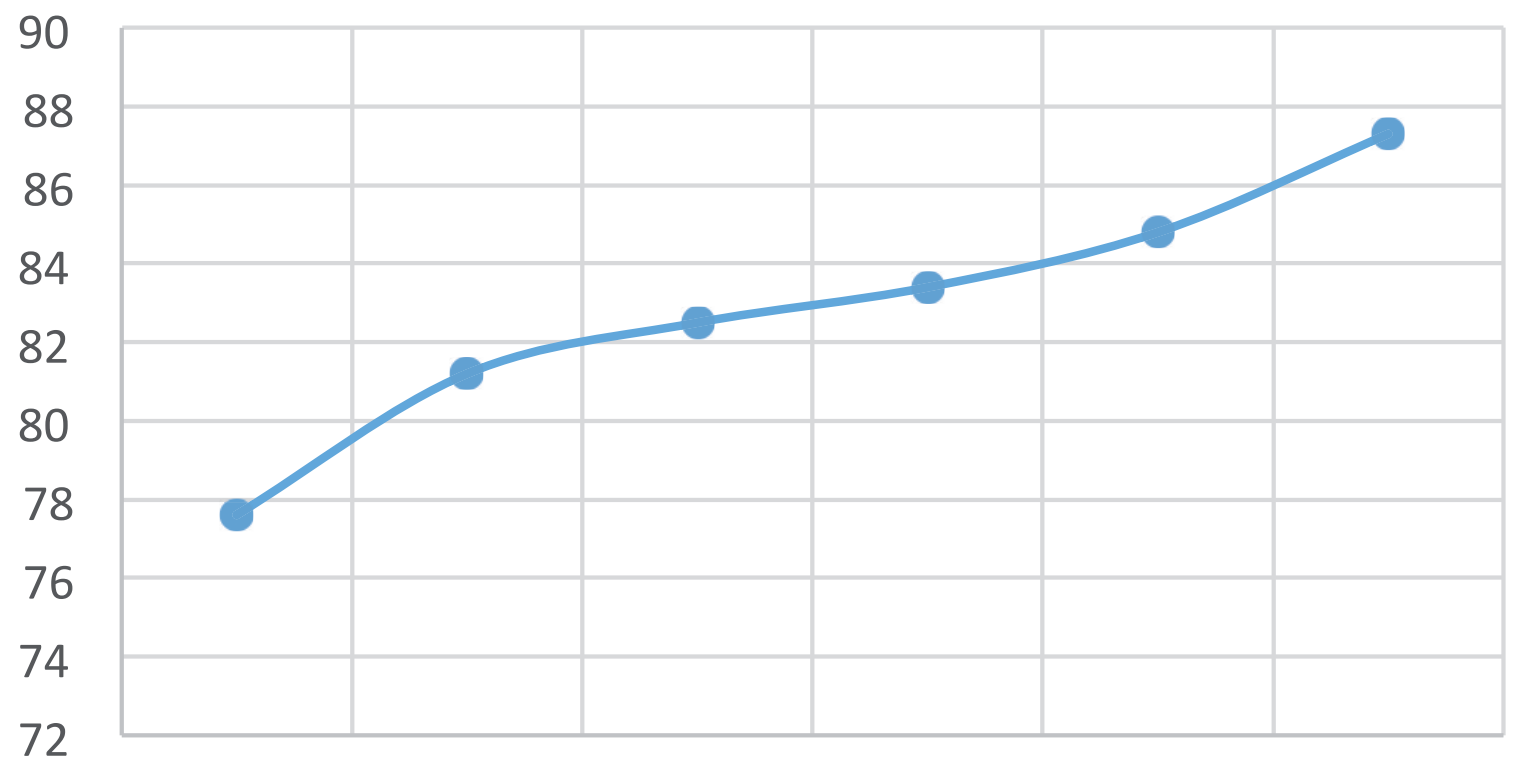

1990-1995 2005-2010 2010-2015 2015-2020 2025-2030 2025-2050

Fuente: World Population Prospetcs. The 2017 Revision. Key findings \& avance tables. ONU, 2017.

Una de las causas de este aumento de la población adulta mayor responde a que las personas nacidas en el conocido como BabyBoom español (1958-1977) llegarán a su edad de jubilación en torno a 2024 (Abellán et al., 2018) con el consiguiente esperado aumento de la demanda de actividades formativas para las personas mayores. 


\section{I.I. Incorporación del AVL en las agendas internacionales en materia educativa}

Los Objetivos de Desarrollo del Milenio (ODM) adoptados en la Cumbre del Milenio por Naciones Unidas el 13 de septiembre de 2000 a través de su Declaración del Milenio, planteaban como objetivo relacionado con la educación lograr la enseñanza primaria universal. Más concretamente la ONU (2000) establecía como meta para el año 2015:

Velar por que, para ese mismo año, los niños y niñas de todo el mundo puedan terminar un ciclo completo de enseñanza primaria y por qué tanto las niñas como los niños tengan igual acceso a todos los niveles de la enseñanza (p. 5).

En principio puede parecer una meta muy loable, sin embargo, los ODM, en relación con la educación, adolecían de varias carencias. La primera y fundamental es su alcance geográfico. Son Objetivos pensados desde el norte hacia el sur y se centraban en, únicamente, el desarrollo de estos últimos. Por otra parte, tal como establecía la meta señalada, tan solo se hacía hincapié en el ámbito de la educación primaria, obviando el resto de etapas formativas del ciclo de vida de las personas (UNESCO, 2016a). Paralelamente a la aprobación de los ODM, en abril de 2000 se celebró en Dakar el Foro Mundial sobre la Educación en el cual se aprobó el Marco de Acción de Dakar y que, además de ratificar los acuerdos de Jomtien en relación al derecho a la educación de todas las personas, independiente de la edad, el género y la procedencia, establece que:

[...] todos los niños, jóvenes y adultos, en su condición de seres humanos tienen derecho a beneficiarse de una educación que satisfaga sus necesidades básicas de aprendizaje en la acepción más noble y más plena del término, una educación que comprenda aprender a asimilar conocimientos, a hacer, a vivir con los demás y a ser. Una educación orientada a explotar los talentos y capacidades de cada persona y desarrollar la personalidad del educando, con objeto de que mejore su vida y transforme la sociedad (UNESCO, 2000, p. 8).

De esta declaración podemos extraer varios aspectos que 15 años después se incluirían en el cambio de paradigma que supondrían los Objetivos de Desarrollo Sostenible (ODS) en relación a los ODM con respecto a la educación. El primero es la universalidad de los mismos. El segundo es la focalización de la educación en desarrollar las capacidades para vivir una vida plena, es decir, se centra en el concepto de desarrollo humano introducido por el Programa de las Naciones Unidas para el Desarrollo (PNUD) en 1990. Y, por último, hace referencia a la dimensión transformadora de la educación, pilar de la Educación para la Ciudanía Global (EpCG).

En 2014 se celebró en Mascate la Reunión Mundial sobre la Educación para Todos (UNESCO, 2014), en la que se acordaron tanto el objetivo como las metas en 
materia de educación que posteriormente sirvieron de fundamento al Grupo de Trabajo Abierto sobre los ODS para el establecimiento de las metas y objetivos propuestos por la ONU.

En mayo de 2015, se celebró en Incheon el Foro Mundial sobre la Educación 2015 en el que aprobaron la Declaración de Incheon (UNESCO, 2015). En dicho foro se dieron cita gobiernos, organismos multilaterales y bilaterales, representantes de la sociedad civil, docentes y sector privado y marcaron el camino a seguir en los siguientes 15 años en materia de educación.

En el apartado 5 del preámbulo de dicha declaración, se establece:

Nuestra visión es transformar las vidas mediante la educación, reconociendo el importante papel que desempeña la educación como motor principal del desarrollo y para la consecución de los demás ODS propuestos. Nos comprometemos con carácter de urgencia con una agenda de la educación única y renovada que sea integral, ambiciosa y exigente, sin dejar a nadie atrás. Esta nueva visión se recoge plenamente en el ODS 4 propuesto "Garantizar una educación inclusiva y equitativa de calidad y promover oportunidades de aprendizaje permanente para todos" y sus metas correspondientes (UNESCO, 2015, p. 7).

Este nuevo objetivo, así como sus metas e indicadores, hacen hincapié en diferentes aspectos de una educación transformadora: inclusiva y equitativa, igualitaria, de calidad y a lo largo de toda la vida.

Fue finalmente en septiembre de 2015 cuando la Asamblea General de la ONU, aprobó el documento Transformar nuestro mundo: la Agenda 2030 para el Desarrollo Sostenible, en el que se establecieron los 17 ODS y sus correspondientes metas. Esta agenda debe marcar el rumbo de los próximos años en favor de las personas, el planeta, la prosperidad, la paz y las alianzas (ONU, 2015a). La educación tendrá un papel primordial para intentar solucionar los principales problemas detectados por la ONU en su informe de evaluación de los ODM y, en particular, con las personas más desfavorecidas a causa de su sexo, edad, discapacidad, etnia o ubicación geográfica (ONU, 2015b).

Con respecto al marco normativo de la educación permanente en Europa, en 2002, el Consejo de Europa establecía su definición más completa, traspasando el aspecto economicista de la misma:

[...] la educación permanente tiene que comprender el aprendizaje desde la etapa de preescolar hasta después de la jubilación, incluyendo todo el espectro del aprendizaje formal, no formal e informal. Además, la educación permanente debería ser entendida como toda actividad de aprendizaje emprendida a lo largo de la vida, con el ánimo de mejorar el saber, las destrezas y las aptitudes desde una visión personal, cívica, social o 
laboral. Finalmente, los principios en este contexto deben ser: el individuo como sujeto del aprendizaje, resaltando la importancia de una auténtica igualdad de oportunidades, y la calidad en el aprendizaje (Consejo Unión Europea, 2002, p. 2).

Cabe destacar las perspectivas cívicas y sociales de la definición, estrechamente ligadas con la $\mathrm{EpD}$, así como que está fundamentada en cuatro pilares que estableció el Informe Delors y que deben ser el objetivo de cualquier aprendizaje: aprender a conocer, aprender a hacer, aprender a vivir juntos y aprender a ser (Delors, 1996).

Por otra parte, es importante señalar que hace referencia tanto al aprendizaje formal, no formal como informal.

Más recientemente, concretamente en 2015, la UNESCO, en el documento Recomendación sobre el aprendizaje y la educación de adultos, estableció los objetivos que deberían cumplir el aprendizaje y la educación de adultos, considerando éstos "...como el centro de un cambio de paradigma hacia el aprendizaje a lo largo de la vida..." (UNESCO, 2010a, p. 14):

Los objetivos del aprendizaje y la educación de adultos son: a) desarrollar la capacidad de las personas para pensar de forma crítica y actuar con autonomía y sentido de la responsabilidad; b) reforzar la capacidad para afrontar y configurar las evoluciones que se producen en la economía y en el mundo laboral; c) contribuir a crear una sociedad del aprendizaje en la que cada individuo tenga la oportunidad de aprender y participar con plenitud en procesos de desarrollo sostenible, y aumentar la solidaridad de las personas y las comunidades; d) promover la coexistencia pacífica y los derechos humanos; e) fomentar la resiliencia en los adultos jóvenes y en los mayores; f) sensibilizar a la opinión pública acerca de la protección del medio ambiente (UNESCO, 2016b).

Como se puede comprobar, estos objetivos están completamente alineados con la agenda de Desarrollo Sostenible 2030 en materia de educación y contribuyen al logro del resto de ODS.

Por otra parte, diferentes organismos entre los que podemos destacar la OMS, han revisado sus paradigmas, en concreto el de envejecimiento activo, para dar cabida a la educación permanente como pilar del mismo junto a salud, participación y seguridad (OMS, 2002).

La necesidad del Aprendizaje a lo Lardo de la Vida (ALV) está justificada por los continuos cambios que nuestra sociedad está experimentando, y a muchos de los cuales, las personas mayores tienen dificultades para adaptarse. El Instituto de Mayores y Servicios Sociales (IMSERSO) en su publicación Envejecimiento Activo. Libro blanco (2011) identificó algunos de ellos: 
a) La sociedad de la información y el conocimiento. La tecnología ha propiciado una expansión del conocimiento y la principal característica es la velocidad a la que se genera. Es necesario formar a nuestros mayores para que esa brecha digital no suponga una nueva causa de exclusión, desigualdad e inequidad.

b) La globalización. Esta conlleva transformaciones tanto individuales como sociales. Únicamente desde una perspectiva Glocal, en la que unamos el conocimiento de los demás (lo global) con el nuestro propio (lo local), podremos afrontar los cambios necesarios para una convivencia exitosa.

\section{I.2. Los Programas Universitarios para Mayores}

Tal como hemos señalado en el apartado anterior, las instituciones académicas y educativas juegan un papel primordial en la consecución de los objetivos planteados desde el paradigma Educación permanente. Dentro del amplio catálogo de actividades formativas para las personas que se encuentran en la etapa de adultez tardía, tales como los PUM, Aulas de Tercera Edad, Programas Municipales para Mayores, Universidades Populares, Programas Culturales de los Centros de Día, Voluntariado Cultural de Mayores, Asociacionismo Cultural de Mayores, congresos, cursos, jornadas, conferencias, viajes culturales, intercambios, etc. (Junta de Andalucía, 2010), en España, tal como establecen Gil et al. (2014) son tres las instituciones que ofrecen una mayor oferta de educación para personas mayores:

a) Las universidades a través de los PUM por medio de programas educación estructurados, en los que se incluyen gran número de actividades no formales.

b) Las asociaciones, centradas en la educación informal.

c) Los centros de educación para personas adultas, más formales y orientados especialmente al mundo laboral.

Para el presente trabajo, nos centraremos en los PUM.

Tal como señala Cabedo (2010), la Ley Orgánica de Universidades de 2007 en su preámbulo establece que "Las Universidades [...] han de dar adecuada respuesta a las necesidades de formación a lo largo de toda la vida y abrirse a quienes, a cualquier edad, deseen acceder a su oferta cultural o educativa" (p. 9).

Basados en el modelo francés de la Universidad de la Tercera Edad establecido en Toulouse en 1973 por el profesor de la Universidad de Ciencias Sociales, Pierre Vellas, y cuya principal característica es el alto grado de actividades educativas 
e investigadoras combinadas en diversas formas: desde una total integración en la estructura universitaria, pasando por una estrecha colaboración con las instituciones de educación superior, hasta la total independencia (Gil et al., 2014), las PUM desembarcaron en España en 1992 en la localidad de Alcalá de Henares (Escuder, 2017).

A nivel español, Lemieux (1997) planteó los objetivos que debían cumplir los PUM:

a) Desarrollar la cultura y la investigación.

b) Responsabilizar al estudiantado de los resultados obtenidos, quienes adoptan un compromiso al asumir personalmente los resultados obtenidos.

c) Orientar el aumento de los saberes y del saber-hacer hacia un desarrollo del saber-ser.

Hasta llegar a convertirse en como hoy los conocemos, es decir, programas educativos no formales con Plan de Estudios propio, y con todas las características propias de la enseñanza superior, los PUM, pasaron por varias etapas. Una primera en la que eran servicios educativos concebidos como programas culturales de tiempo libre y cuya finalidad era la de entretener o favorecer las relaciones sociales. Y una segunda en la que eran concebidos como actividades educativas para la participación y mejora de los conocimientos de las personas mayores y cuyo objetivo era la intervención de éstas en los problemas sociales existentes (Junta de Andalucía, 2010).

Valle (2014), basándose en la investigación de Martorell et al. (2009) identifica cuatro tipos de programas:

a) Específicamente dedicados a las personas mayores, con currículos propios y realizados en aulas diferenciadas del resto de actividad docente universitaria.

b) Integrados con aulas intergeneracionales entre estudiantes mayores y jóvenes.

c) Mixtos, resultado de la combinación de los anteriores

d) Acciones formativas organizadas por el propio estudiantado mayor.

En la actualidad, en España podemos encontrar 73 PUM (incluyendo las aulas de extensión desagregadas de los programas principales) en 63 universidades, de las cuales 48 son públicas (Subires y Delgado, 2017).

En relación a los datos del alumnado participante en los PUM, resulta complicado acceder a esta información, ya que muchas de las universidades no la tienen 
accesible. Los datos más fiables, aunque incompletos, son los proporcionados por la Asociación Estatal de Programas Universitarios para Personas Mayores (AEPUM, 2018), que en la actualidad cuenta con 45 universidades miembro, que nos sirven para comprobar el ascenso del número de matriculaciones en los últimos años (ver Figura 2).

\section{FIGURA 2. Evolución del alumnado de los PUM es España}

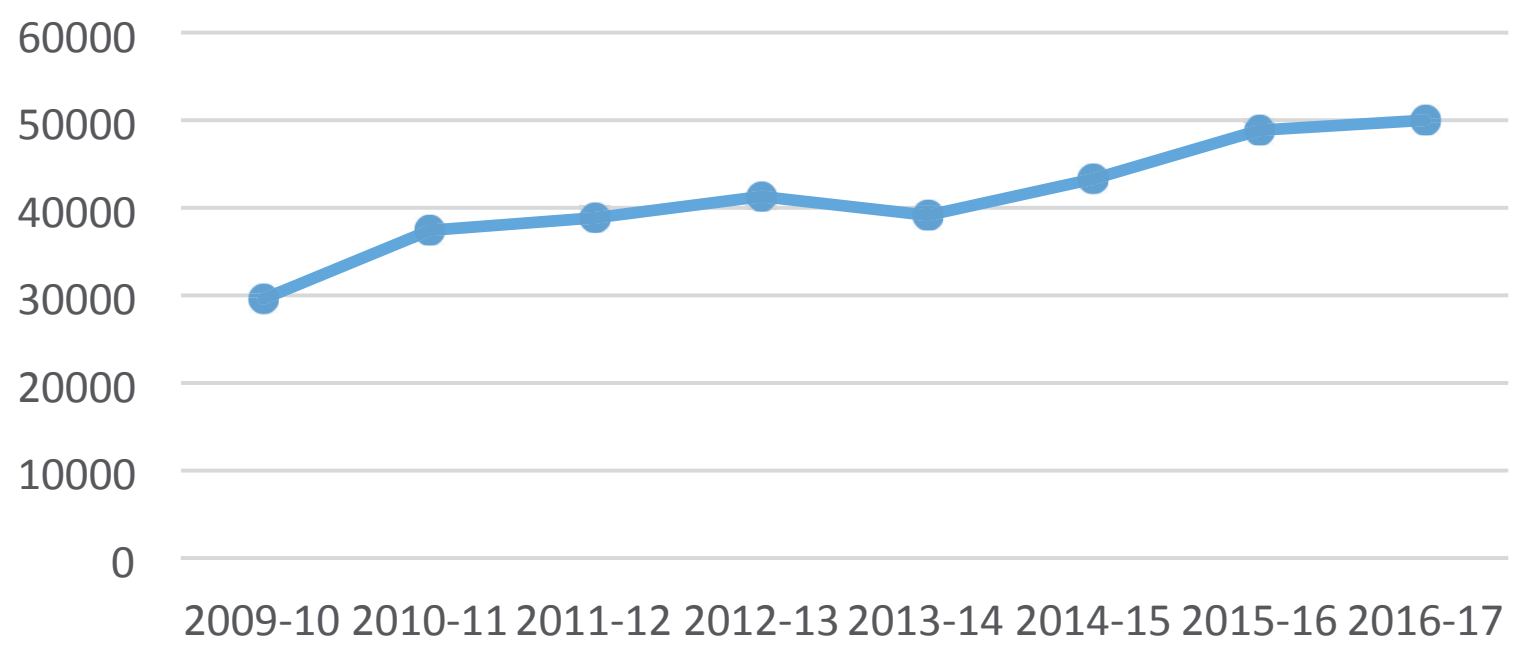

Fuente: AEPUM. 2017.

\section{I.3. Educación para el Desarrollo}

Ortega, en la Estrategia de Educación para el Desarrollo de la cooperación española, publicada en 2007 y que en la actualidad continúa siendo el marco normativo de referencia en España, definió la EpD como:

Proceso educativo (formal, no formal e informal) constante encaminado, a través de conocimientos, actitudes y valores, a promover una ciudadanía global generadora de una cultura de la solidaridad comprometida en la lucha contra la pobreza y la exclusión, así como con la promoción del desarrollo humano y sostenible (Ortega, 2007, p.19).

En relación a los objetivos de la $\mathrm{EpD}$, es difícil sintetizar en un listado los propuestos por las y los diferentes autores, sin embargo, todos coinciden en el objetivo último de la EpD: la transformación social. Para ello, según establece la Estrategia de Educación para el Desarrollo de la cooperación española, es necesario que ésta incida en una serie de principios fundamentales y conceptos clave, expuestos a modo resumen en el Cuadro 1. 


\section{CUADRO I. Principios fundamentales y conceptos clave de la EpD}

Principios fundamentales

Justicia Social.

Corresponsabilidad.

No discriminación.

lgualdad.

Equidad.

Empoderamiento.

Solidaridad.

Participación.

Diálogo.

\section{Conceptos clave}

Desarrollo Humano Sostenible.

Ciudadanía global.

Bien común.

Codesarrollo.

Educación en valores.

Educación para la Paz, los DDHH y la democracia.

Educación intercultural.

Educación ambiental.

Conciencia crítica.

$$
\text { EpCG. }
$$

Consumo responsable.

Comercio justo.

Fuente: Ortega (2007).

El carácter global señalado de la EpD nos conduce a hablar del concepto de Educación para una Ciudadanía Global (EpCG), tal como afirman Boni y León (2013), al hacer referencia a la EpD de quinta generación. Las fuentes consultadas utilizan indistintamente ambos términos. Cabe señalar que ya existen autores que plantean una sexta generación de EpD conocida como Educación al Postdesarrollo, cuyo eje principal es la descolonización del imaginario actual en relación al concepto de desarrollo y abogan por la construcción de un nuevo orden social en el que la educación sirva de herramienta emancipadora del actual sistema economicista (Lozano, 2009). El último Congreso de Educación para el Desarrollo celebrado en Vitoria-Gasteiz en octubre de 2014, giró en torno a esta idea emancipadora de la EpD y se centró en cuatro líneas de actuación: construcción del sujeto político, comunicación para la transformación, análisis de las relaciones de poder y análisis de procesos educativos (Celorio, 2014).

A la hora de analizar los componentes de la EpCG, las diversas autoras y autores consultados, aunque coinciden en sus elementos, no presentan acuerdo en la nomenclatura que los engloba. Mientras Celorio (2013) identifica cuatro dimensiones de la $\mathrm{EpD}$ que le otorgan un carácter global: dimensión política, pedagógica, intercultural y ética, Ortega (2007) señala como dimensiones lo que posteriormente se señalan como estrategias de actuación (ver Figura 3) para la transformación social 
que este nuevo enfoque de EpD requiere: Sensibilización, Formación, Investigación e Incidencia Política y Movilización social (Baselga et al., 2004; Celorio, 2013), siempre desde la perspectiva que debe apoyarse en dos pilares: el cognitivo (de conocimiento de la realidad, de análisis, de razonamiento, etc.) y el actitudinal (de valores y virtudes, de actitudes y comportamientos), y que su implementación tiene que realizarse tanto como asignatura como a nivel transversal en todos los niveles educativos (Argibay et al., 2009). A nivel teórico, nosotros nos alineamos con el modelo propuesto por Baselga et al. (2004) y Celorio (2013), ya que consideramos conveniente la diferenciación entre ambas (dimensiones y estrategias).

\section{FIGURA 3. Dimensiones y estrategias de actuación en EpD}

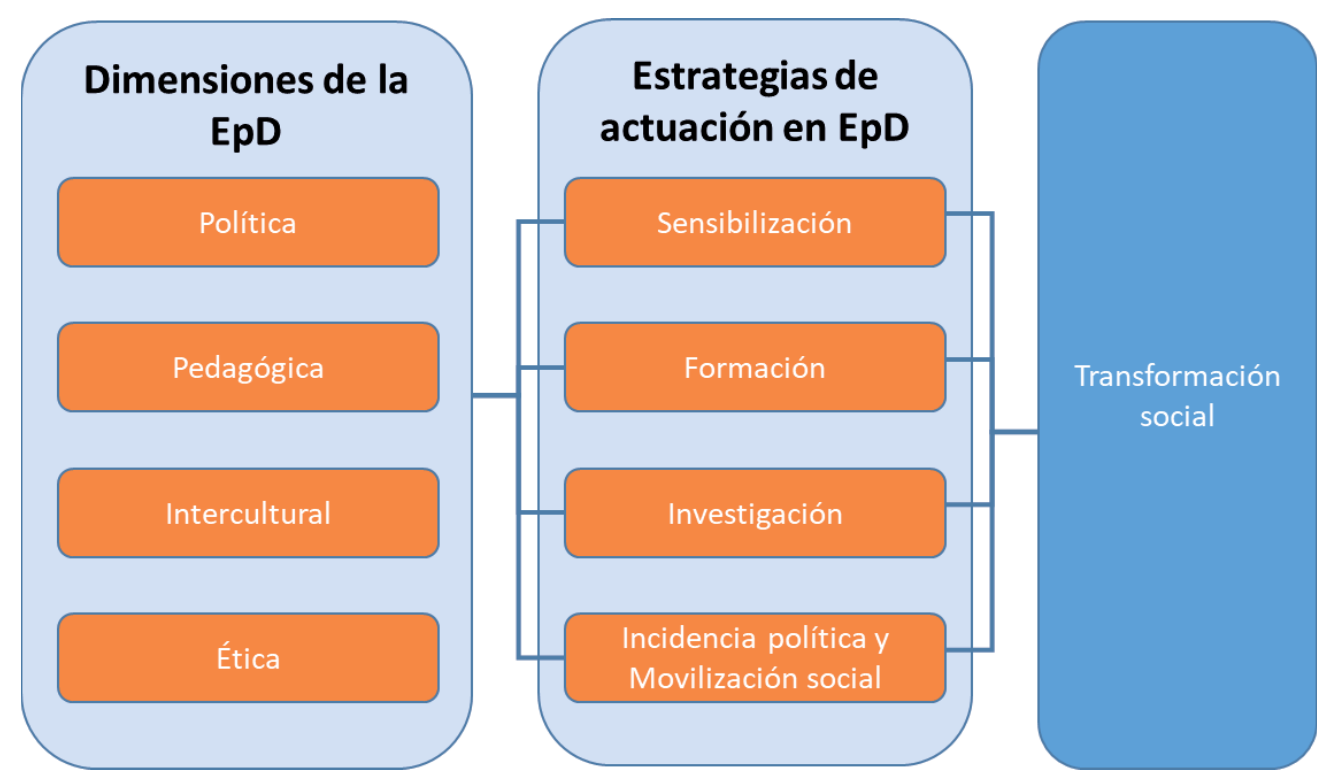

Fuente: Elaboración propia a partir de BASELGA et AL. (2004) y CeLORIO (2013).

En relación a la función de las universidades en relación a la EpD, El Marco de Acción para la realización del Objetivo de Desarrollo Sostenible 4, consecuencia del Foro Mundial sobre la Educación, celebrado en Incheon en 2015, hace referencia explícita al papel que las universidades juegan en la construcción del pensamiento crítico, uno de los principales objetivos de la EpD, y en la generación y transmisión de conocimientos encaminados a favorecer el desarrollo social, cultural, ecológico y económico (UNESCO, 2015).

Por su parte, el Comité Español Universitario de Relaciones Internacionales (CEURI), en el año 2000, desarrolló la Estrategia de Cooperación Universitaria al Desarrollo, en la cual estableció las funciones que deberían desarrollar los centros de 
enseñanza superior en relación con la Cooperación al Desarrollo y en aras de la consecución de un desarrollo global: formación y educación, incidir en el entorno social, principalmente a través de la sensibilización y la $\mathrm{EpD}$, investigación para el desarrollo y transferencia tecnológica (CEURI, 2000).

Centrándose en la estrategia de Formación, Boni y Pérez (2006) confeccionan un modelo de EpD como educación para la Ciudadanía Cosmopolita. Este modelo se basa en cuatro fundamentaciones, ampliamente desarrolladas por Boni (2005):

a) Ideológica, basada en el modelo de desarrollo a escala humano propuesto por Max Neef y Sen con vocación universalista e incorporando los Derechos Humanos en su discurso. Por otra parte, esta fundamentación también descansa sobre la idea de pertenencia a una comunidad mundial de iguales introducida por Nassbaum y conocida como ciudadanía cosmopolita. Ambas incorporan propuestas políticas con el fin de la creación de un nuevo multilateralismo.

b) Axiológica, basada en los valores promulgados por la Declaración Universal de los Derechos Humanos

c) Pedagógica, basada en las teorías de la educación en valores como construcción de la personalidad moral, como las expuestas por Burraxais o Martínez Martin, en la educación popular cuya finalidad principal es la emancipación de las personas, y que cuenta con Paulo Freire como máximo exponente. Por último, esta fundamentación se basa en la teorías de educación global propuestas por Yus o Hicks, que inciden en incorporar la dimensión de interdependencia entre lo local y global.

d) Psicológica, basada en las teorías del desarrollo del juicio moral de Kohlberg y en las teorías socioconstructivistas del aprendizaje social de Vigotski. Cabría añadir las teorías del aprendizaje significativo propuestas por Novak.

En base a estas cuatro fundamentaciones, Boni y Pérez (2006) establecen, a la hora de confeccionar un currículo, una clasificación de ideas clave a cumplir por la EpD y que se dividen en tres dimensiones: cognitiva, procedimental y actitudinal (ver Figura 4), y siempre desde el enfoque de las capacidades propuesto por el PNUD (Boni, et al., 2014). 


\section{FIGURA 4. Dimensiones e ideas clave del modelo de EpD}
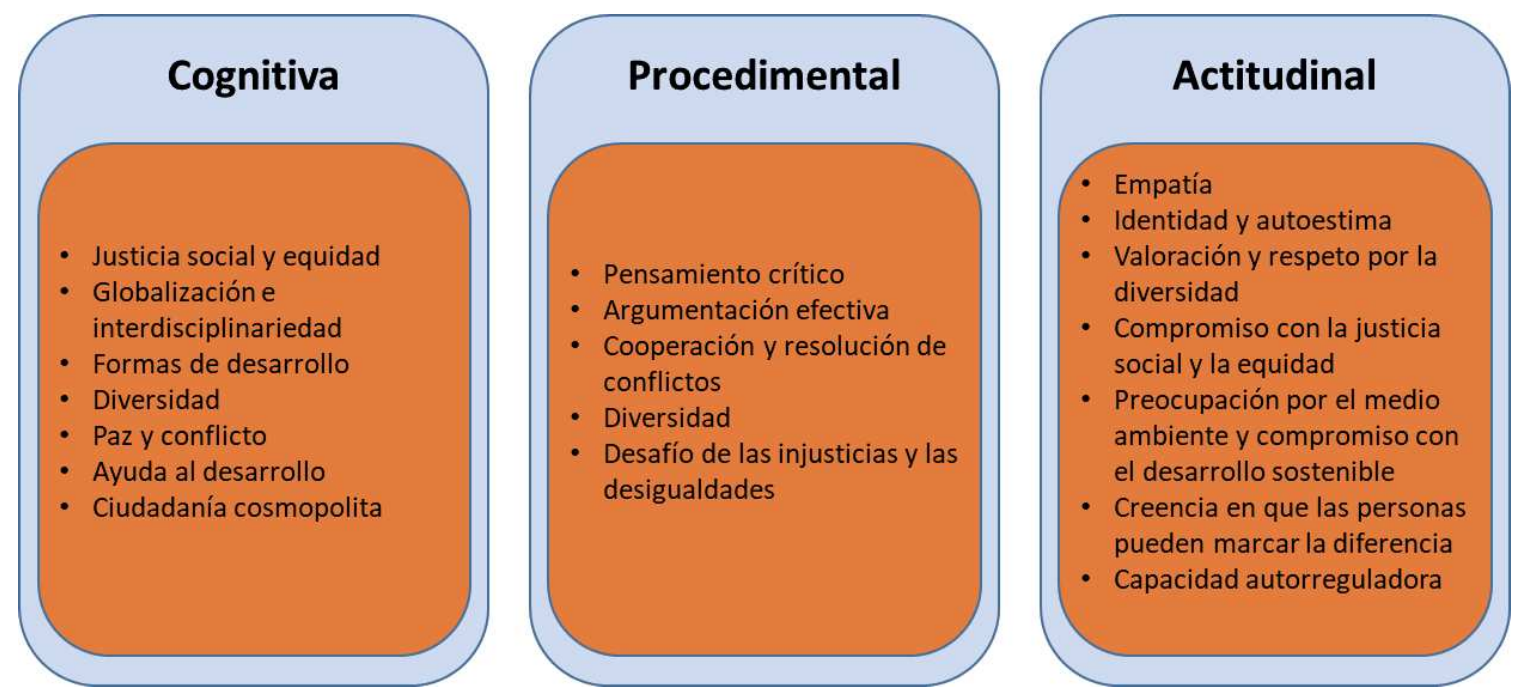

Fuente: BONI Y PÉREZ (2006).

Boni et al. (2013) ampliaron el modelo introduciendo en cada una de las tres dimensiones una propuesta de atributos que consideraban necesarios para la consecución de una ciudadanía global (ver Cuadro 2).

Ahondando en ese concepto de globalidad, la autoría señala la importancia de la idea de cosmopolitismo transformador o emancipador, diferenciándolo de conceptos como globalización o transnacionalización o de procesos impulsados desde arriba, ejemplo del eurocentrismo, e identificando que éste puede surgir en cualquier parte del mundo e impulsado tanto por individuos, como colectivos u organizaciones. También señalan que este tipo de cosmopolitismo crea puntos de unión entre las diferencias de cada sociedad.

Por último, apuntan que "El cosmopolitismo transformador actúa en el vacío entre lo local y lo local, conectando las dos realidades y creando, por tanto, espacios transnacionales que promueven los cambios sociales" (Boni et al., 2014, p. 51), identificando a este tipo de relación con el concepto de Glocal, ya señalado anteriormente. 


\section{CUADRO 2. Atributos para potenciar en un currículo para la ciudadanía global}

\begin{tabular}{|c|c|}
\hline Dimensión & Atributos \\
\hline \multirow[t]{5}{*}{$\begin{array}{l}\text { Conocimiento y } \\
\text { sensibilización }\end{array}$} & $\begin{array}{l}\text { Justicia social y equidad: comprensión de las desigualdades e injusticias } \\
\text { dentro y entre las sociedades. Conocimiento de las necesidades huma- } \\
\text { nas y de los derechos humanos sobre todo de los más empobrecidos. }\end{array}$ \\
\hline & $\begin{array}{l}\text { Comprensión de las interrelaciones económicas, políticas, sociales, } \\
\text { culturales y ambientales entre el Norte y el Sur. }\end{array}$ \\
\hline & $\begin{array}{l}\text { Comprensión de las diversidades que existen dentro de las sociedades y } \\
\text { cómo las vidas de los otros pueden enriquecer la nuestra. Conocimiento } \\
\text { de los prejuicios hacia la diversidad y cómo pueden ser combatidos. }\end{array}$ \\
\hline & $\begin{array}{l}\text { Comprender el significado ético de la comunidad mundial de iguales, } \\
\text { de nuestras responsabilidades como ciudadanos globales y de las } \\
\text { propuestas políticas para su realización. }\end{array}$ \\
\hline & Conocer el poder y cómo tener impacto para revertir situaciones. \\
\hline \multirow[t]{5}{*}{ Habilidades } & Capacidad de negociar y llegar a compromisos. \\
\hline & Capacidad de influir en otras personas y ejercer el liderazgo. \\
\hline & Capacidad de comunicar y colaborar con otros/as. \\
\hline & Capacidad de deliberar, tener voz y escuchar. \\
\hline & Capacidad de imaginar y realizar proyectos orientados al bien común. \\
\hline \multirow[t]{8}{*}{ Actitudes } & $\begin{array}{l}\text { Respeto y reconocimiento por el medio ambiente y la vida dentro de él. } \\
\text { Voluntad de considerar las futuras generaciones y actuar de manera } \\
\text { responsable. }\end{array}$ \\
\hline & $\begin{array}{l}\text { Empatía: sensibilidad hacia los sentimientos, necesidades y vidas de } \\
\text { otras personas en el mundo; sentido de una humanidad común, de } \\
\text { necesidades comunes y derechos. }\end{array}$ \\
\hline & Identidad y autoestima: sentimiento de la propia valía e individualidad. \\
\hline & $\begin{array}{l}\text { Voluntad de vivir con las diferencias y de resolver conflictos de manera } \\
\text { no violenta. }\end{array}$ \\
\hline & Conciencia crítica; actitud investigadora y no conformista. \\
\hline & $\begin{array}{l}\text { Compromiso con la justicia social y la equidad: interés y preocupación } \\
\text { por los temas globales. }\end{array}$ \\
\hline & $\begin{array}{l}\text { Compromiso con la justicia y disposición para trabajar para un mundo } \\
\text { más justo. }\end{array}$ \\
\hline & $\begin{array}{l}\text { Sentido de la eficacia y de que se puede tener un impacto en la vida } \\
\text { de los demás. Optimismo hacia la transformación social. }\end{array}$ \\
\hline
\end{tabular}

Fuente: Boni et al. (2014). 
Es precisamente esta globalidad de la quinta generación de EpD la que promueve la nueva agenda internacional de desarrollo a través de sus ODS, en los que se abandona el paradigma norte-sur para hablar de un nuevo paradigma local-global, en el que todos los países son responsables del desarrollo humano de sus habitantes y no únicamente en aquellos países más desfavorecidos tal como señalamos en el apartado correspondiente a las Agendas Internacionales en Educación.

De hecho, la ONU, en su documento Transformar nuestro mundo: la Agenda 2030 para el Desarrollo Sostenible, establece en su meta 4.7 la EpD, en todos los niveles educativos, como una de las herramientas para alcanzar este desarrollo:

De aquí a 2030, asegurar que todos los alumnos adquieran los conocimientos teóricos y prácticos necesarios para promover el desarrollo sostenible, entre otras cosas mediante la educación para el desarrollo sostenible y los estilos de vida sostenibles, los derechos humanos, la igualdad de género, la promoción de una cultura de paz y no violencia, la ciudadanía mundial y la valoración de la diversidad cultural y la contribución de la cultura al desarrollo sostenible (ONU, 2015a, p.20)

\subsection{Objetivo de investigación}

El objetivo general del presente trabajo es analizar el estado actual de la aplicación de las dimensiones de Educación para el Desarrollo, según el modelo revisado, en los Programas Universitarios para Mayores en España.

\section{Método}

La metodología utilizada para realizar el análisis es la revisión sistemática de la bibliografía sobre la temática abordada siguiendo los principios de la declaración PRISMA (PRISMA, 2018).

\section{I. Procedimiento}

La revisión bibliográfica se realiza en el espacio temporal de 2011 a 2018, ya que fue en 2010 cuando se introdujo la perspectiva del Aprendizaje a lo Largo de la Vida como cuarto pilar del paradigma del Envejecimiento Activo. Las palabras claves utilizadas en la revisión bibliográfica fueron: Universidad, Aprendizaje a lo Largo de la Vida, Programas Universitarios para Mayores y Educación para el Desarrollo. Por un lado, las bases de datos consultadas fueron Scopus, Web of Science y ProQuest y por otro la revista de divulgación científica Educational Gerontology. 
Posteriormente se realizó una revisión para seleccionar los que se adecuaban al objetivo de la investigación estableciendo unos criterios de inclusión y exclusión, los cuales se describen en el Cuadro 3.

\section{CUADRO 3. Criterios de inclusión y exclusión}

\begin{tabular}{|c|c|}
\hline Criterio de inclusión & \begin{tabular}{c} 
Criterio de exclusión \\
\hline Revistas científicas
\end{tabular} \\
\hline Ámbito territorial: España & $\begin{array}{c}\text { Ámb educativo distinto del } \\
\text { universitario }\end{array}$ \\
\hline Grupo destino: Adultos mayores & Duplicados \\
\hline Acceso al documento completo & No componentes EpD \\
\hline
\end{tabular}

Fuente: Elaboración propia.

Debido a la ausencia de artículos científicos en relación a la cuestión planteada, se decide realizar una segunda fase de revisión, acudiendo a otras fuentes primarias de información. En este caso se revisaron tanto las ponencias como las comunicaciones de las actas de los Encuentros Estatales de los Programas Universitarios para Mayores celebrados en España desde el año 2011 en base a los componentes de las dimensiones cognitiva, procedimental y actitudinal del modelo de EpD establecido por Boni y Pérez (2006). Además, también se revisaron las comunicaciones de los Congresos Universidad y Cooperación al Desarrollo en sus líneas temáticas relacionadas con la educación y la formación en el ámbito universitario y los Congresos de Educación para el Desarrollo desde 2011 (Cuadro 4).

\section{CUADRO 4. Actas de congresos analizadas}

\begin{tabular}{|l|l|l|}
\hline Año & \multicolumn{1}{|c|}{ Congreso } & \multicolumn{1}{c}{ Título } \\
\hline 2011 & $\begin{array}{l}\text { XII Encuentro Estatal y IV } \\
\text { Congreso lberoamerica- } \\
\text { no de PUM }\end{array}$ & $\begin{array}{l}\text { Aprendizaje a lo largo de la vida, envejeci- } \\
\text { miento activo y cooperación internacional en } \\
\text { los programas universitarios para mayores }\end{array}$ \\
\hline 2011 & $\begin{array}{l}\text { V Congreso Universi- } \\
\text { dad y Cooperación al } \\
\text { Desarrollo }\end{array}$ & $\begin{array}{l}\text { Cooperación universitaria al desarrollo ante } \\
\text { los retos de un mundo en crisis }\end{array}$ \\
\hline
\end{tabular}

${ }^{3}$ Identificamos los componentes de la EpD con los conceptos clave expuestos en el Cuadro 1. 


\begin{tabular}{|l|l|l|}
\hline 2013 & $\begin{array}{l}\text { XIII Encuentro Estatal de } \\
\text { PUM }\end{array}$ & $\begin{array}{l}\text { Nuevos tiempos, nuevos retos para los progra- } \\
\text { mas universitario para mayores }\end{array}$ \\
\hline 2013 & $\begin{array}{l}\text { VI Congreso Universi- } \\
\text { dad y Cooperación al } \\
\text { Desarrollo }\end{array}$ & Desarrollo humano y universidad \\
\hline 2014 & $\begin{array}{l}\text { IV Congreso de Educa- } \\
\text { ción para el Desarrollo }\end{array}$ & $\begin{array}{l}\text { Cambiar la educación para cambiar el mun- } \\
\text { do... jPor una acción educativa emancipadora! }\end{array}$ \\
\hline 2015 & $\begin{array}{l}\text { XIV Encuentro Estatal de } \\
\text { PUM }\end{array}$ & $\begin{array}{l}\text { Nuevos perfiles de alumnos en las Aulas de } \\
\text { Mayores. Reflexiones en torno a sus percep- } \\
\text { ciones y expectativas sobre los programas } \\
\text { universitarios para mayores }\end{array}$ \\
\hline 2017 & $\begin{array}{l}\text { XV Encuentro Estatal de } \\
\text { PUM }\end{array}$ & $\begin{array}{l}\text { Los programas universitarios para mayores } \\
\text { como elemento estratégico en la formación } \\
\text { para toda la vida }\end{array}$ \\
\hline 2017 & $\begin{array}{l}\text { VI Congreso Universi- } \\
\text { dad y Cooperación al al } \\
\text { Desarrollo }\end{array}$ & $\begin{array}{l}\text { La universidad y los objetivos de desarrollo } \\
\text { sostenible }\end{array}$ \\
\hline
\end{tabular}

Fuente: Elaboración propia.

\subsection{Análisis y resultados}

La búsqueda en las bases de datos señaladas anteriormente dio como resultado el número de artículos que se muestran en el Cuadro 5.

\section{CUADRO 5. Artículos de las bases de datos consultadas en función de las palabras clave}

\begin{tabular}{|l|c|}
\hline \multicolumn{1}{|c|}{ Base de datos } & Artículos \\
\hline ProQuest & 268 \\
\hline Scopus & 1 \\
\hline Web of Science & 1 \\
\hline Educational Gerontology & 48 \\
\hline
\end{tabular}

Fuente: Elaboración propia. 
Tras la aplicación de los criterios de inclusión y exclusión señalados en el Cuadro 3 , el número de artículos seleccionados se muestran en el Cuadro 6.

\section{CUADRO 6. Artículos seleccionados de las bases de datos consultadas tras aplicación de criterios}

\begin{tabular}{|l|c|}
\hline \multicolumn{1}{|c|}{ Base de datos } & Artículos \\
\hline ProQuest & 1 \\
\hline Scopus & 1 \\
\hline Web of Science & 0 \\
\hline Educational Gerontology & 1 \\
\hline
\end{tabular}

En los Cuadros 7, 8 y 9 se muestran el número de documentos revisados y seleccionados de las Actas de los Encuentros Estatales de PUM, los Congresos Universidad y Cooperación al Desarrollo y los Congresos de Educación para el Desarrollo, respectivamente.

CUADRO 7. Documentos de Actas de los

Encuentros Estatales de PUM revisados y seleccionados

\begin{tabular}{|c|c|c|}
\hline Año & Revisados & Seleccionados \\
\hline 2011 & 99 & 8 \\
\hline 2013 & 47 & 5 \\
\hline 2015 & 45 & 3 \\
\hline 2017 & 25 & 2 \\
\hline & 216 & 18 \\
\hline
\end{tabular}

Fuente: Elaboración propia. 
CUADRO 8. Documentos de Actas de los

Congresos Universidad y Cooperación al

Desarrollo revisados y seleccionados

\begin{tabular}{|c|c|c|}
\hline Año & Revisados & Seleccionados \\
\hline 2011 & 21 & 0 \\
\hline 2013 & 19 & 0 \\
\hline 2017 & 21 & 0 \\
\hline & 61 & 0 \\
\hline
\end{tabular}

Fuente: Elaboración propia.

CUADRO 9. Documentos de Actas de los

Congresos Educación para el Desarrollo revisados y seleccionados

\begin{tabular}{|c|c|c|}
\hline Año & Revisados & Seleccionados \\
\hline 2014 & 42 & 0 \\
\hline
\end{tabular}

Fuente: Elaboración propia.

En la Figura 5 se presenta el diagrama de flujo de la información a través de las diferentes fases de la revisión hasta alcanzar los 21 documentos seleccionados (ver Cuadro 10). 
FIGURA 5. Diagrama de flujo de la información a través de las fases de revisión

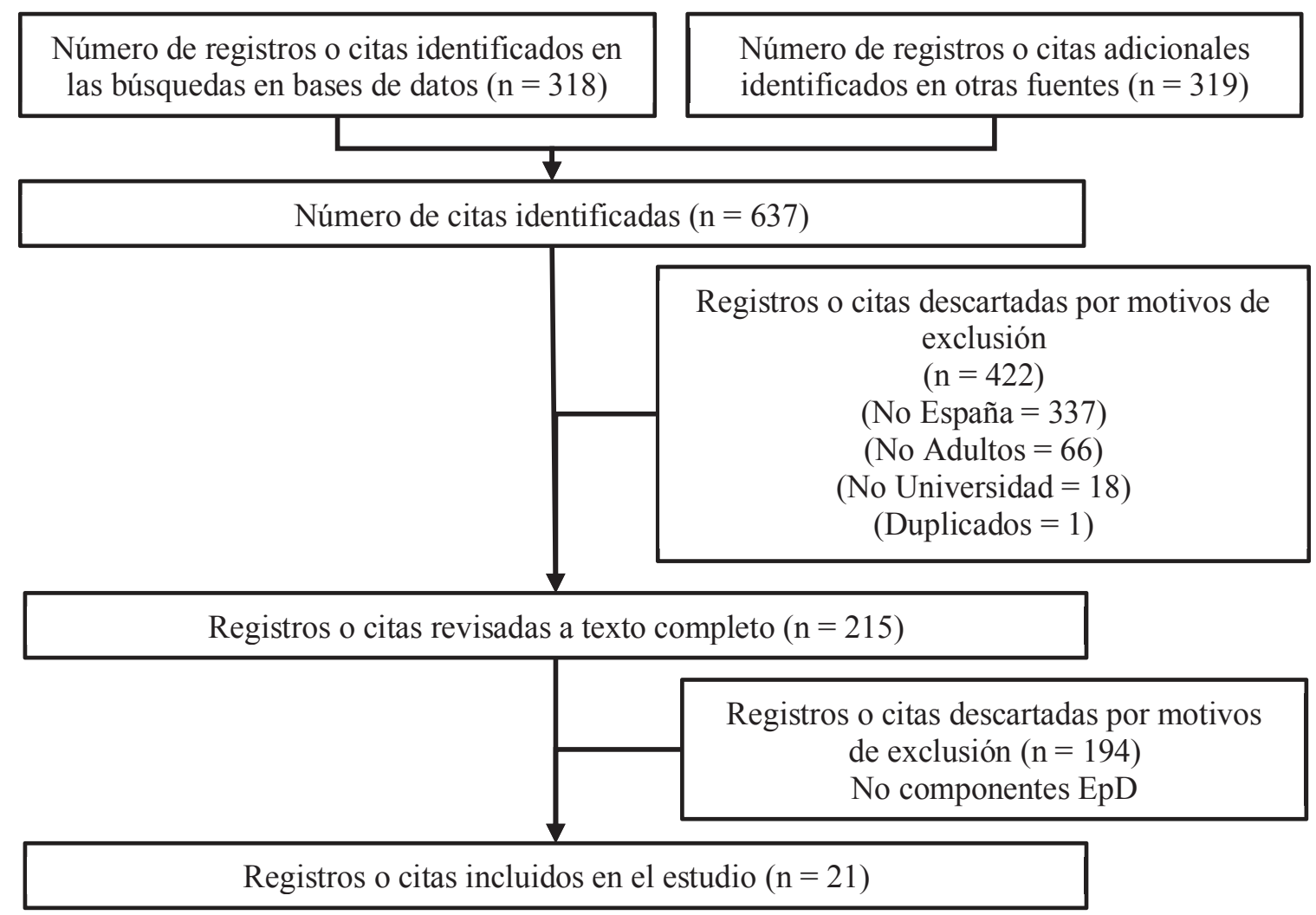

Fuente: Elaboración propia. 
CUADRO 10. Documentos seleccionados en la revisión bibliográfica

\begin{tabular}{|c|c|c|c|c|c|}
\hline Año & Documentos & Autor/es & Universidad & $\begin{array}{l}\text { Tipo de } \\
\text { estudio }\end{array}$ & Revista / Congreso \\
\hline 2011 & $\begin{array}{l}\text { Las Universidades y los Programas Universi- } \\
\text { tarios para Mayores en la educación y for- } \\
\text { mación (el aprendizaje) a lo largo de la vida }\end{array}$ & Lorenzo, J. A. & $\begin{array}{l}\text { Complu- } \\
\text { tense de } \\
\text { Madrid }\end{array}$ & Teórico & $\begin{array}{l}\text { IV Congresolberoame- } \\
\text { ricano de universida- } \\
\text { des para mayores }\end{array}$ \\
\hline 2011 & $\begin{array}{l}\text { Los Programas Universitarios para Personas } \\
\text { Mayores: objetivos y diseño curricular }\end{array}$ & Rodríguez, $\mathrm{A}$. & $\begin{array}{l}\text { Santiago de } \\
\text { Compostela }\end{array}$ & Teórico & $\begin{array}{l}\text { IVCongresolberoame- } \\
\text { ricano de universida- } \\
\text { des para mayores }\end{array}$ \\
\hline 2011 & $\begin{array}{l}\text { Un ejemplo de innovación universitaria: las } \\
\text { experiencias de ocio formativas de los progra- } \\
\text { mas de adultos de la Universidad de Deusto }\end{array}$ & $\begin{array}{l}\text { Lázaro, Y. y Agui- } \\
\text { lar, E. }\end{array}$ & Deusto & Teórico & $\begin{array}{l}\text { IVCongresolberoame- } \\
\text { ricano de universida- } \\
\text { des para mayores }\end{array}$ \\
\hline 2011 & $\begin{array}{l}\text { La formación por competencias en los Pro- } \\
\text { gramas Universitarios para Mayores }\end{array}$ & $\begin{array}{l}\text { García, J. y Delga- } \\
\text { do, J.J. }\end{array}$ & Málaga & Teórico & $\begin{array}{l}\text { IV Congresolberoame- } \\
\text { ricano de universida- } \\
\text { des para mayores }\end{array}$ \\
\hline 2011 & $\begin{array}{l}\text { Buenas prácticas en los Programas Univer- } \\
\text { sitarios para Mayores. Origen y estado de } \\
\text { la cuestión en España }\end{array}$ & Bru, C. & Alicante & Teórico & $\begin{array}{l}\text { IVCongresolberoame- } \\
\text { ricano de universida- } \\
\text { des para mayores }\end{array}$ \\
\hline 2011 & $\begin{array}{l}\text { El papel de las Universidades para Mayores } \\
\text { en el avance hacia una sociedad inclusiva, } \\
\text { intergeneracional y abierta a todas las } \\
\text { edades: el aprendizaje a lo largo de la } \\
\text { vida y la cultura como marco de relaciones } \\
\text { intergeneracionales }\end{array}$ & Holgado, M. A. & $\begin{array}{l}\text { Pontificia de } \\
\text { Salamanca }\end{array}$ & Teórico & $\begin{array}{l}\text { IV Congreso lberoame- } \\
\text { ricano de universida- } \\
\text { des para mayores }\end{array}$ \\
\hline 2011 & $\begin{array}{l}\text { Juntos hacemos universidad: los encuentros } \\
\text { intergeneracionales }\end{array}$ & $\begin{array}{l}\text { Roca, M., Garrido, } \\
\text { N., Guardia, R., } \\
\text { Sancho, T., Rey-Sei- } \\
\text { jo, E. y Yáñez, R. }\end{array}$ & $\begin{array}{l}\text { Complu- } \\
\text { tense de } \\
\text { Madrid }\end{array}$ & Teórico & $\begin{array}{l}\text { IV Congreso lberoame- } \\
\text { ricano de universida- } \\
\text { des para mayores }\end{array}$ \\
\hline
\end{tabular}




\begin{tabular}{|c|c|c|c|c|c|}
\hline 2011 & $\begin{array}{l}\text { La universidad y la globalización del conoci- } \\
\text { miento: movilidad, intercambio, cooperación } \\
\text { nacional y relaciones internacionales }\end{array}$ & Cabedo, S. & $\begin{array}{l}\text { Jaume I de } \\
\text { Castellón }\end{array}$ & Teórico & $\begin{array}{l}\text { IV Congresolberoame- } \\
\text { ricano de universida- } \\
\text { des para mayores }\end{array}$ \\
\hline 2013 & $\begin{array}{l}\text { Hacia una perspectiva europea de la forma- } \\
\text { ción continua en mayores }\end{array}$ & Lorente, $\mathrm{X}$. & Ramon Llull & Teórico & $\begin{array}{l}\text { XIII encuentro estatal } \\
\text { de Programas Univer- } \\
\text { sitarios para Mayores }\end{array}$ \\
\hline 2013 & $\begin{array}{l}\text { Ser para aprender. Los beneficios sociales de } \\
\text { la educación a lo largo de la vida }\end{array}$ & Beltrán, J. & Valencia & Teórico & $\begin{array}{l}\text { XIII encuentro estatal } \\
\text { de Programas Univer- } \\
\text { sitarios para Mayores }\end{array}$ \\
\hline 2013 & $\begin{array}{l}\text { Impacto de los programas universitarios para } \\
\text { mayores en la universidad y en la sociedad }\end{array}$ & Palmero, C. & Burgos & Teórico & $\begin{array}{l}\text { XIII encuentro estatal } \\
\text { de Programas Univer- } \\
\text { sitarios para Mayores }\end{array}$ \\
\hline 2013 & $\begin{array}{l}\text { El espacio europeo de educación superior } \\
\text { (EEES), un ámbito de organización educati- } \\
\text { va en los diseños curriculares de los PUMS. } \\
\text { Competencias básicas, curriculum integrado } \\
\text { y aprendizaje cooperativo. }\end{array}$ & Ávila, R. & Sevilla & Teórico & $\begin{array}{l}\text { XIII encuentro estatal } \\
\text { de Programas Univer- } \\
\text { sitarios para Mayores }\end{array}$ \\
\hline 2013 & $\begin{array}{l}\text { El envejecimiento constructivo: el papel de la } \\
\text { Educación Superior }\end{array}$ & $\begin{array}{l}\text { Fernández, M.I., Ar- } \\
\text { nay, J. y Marrero, J. }\end{array}$ & La Laguna & Teórico & $\begin{array}{l}\text { XIII encuentro estatal } \\
\text { de Programas Univer- } \\
\text { sitarios para Mayores }\end{array}$ \\
\hline 2013 & $\begin{array}{l}\text { Effects of University Programs for Older } \\
\text { Adults: Changes in Cultural and Group } \\
\text { Stereotype, Self-Perception of Aging, and } \\
\text { Emotional Balance }\end{array}$ & $\begin{array}{l}\text { Fernández-Balles- } \\
\text { teros, R., Caprara, } \\
\text { M., Schettini, R., Bus- } \\
\text { tillos, A., Mendoza- } \\
\text { Nunez, V., Orosa, T., } \\
\text {... y Molina, M. A. }\end{array}$ & Varias & Empírico & $\begin{array}{l}\text { Educational } \\
\text { Gerontology }\end{array}$ \\
\hline 2013 & $\begin{array}{l}\text { Los programas Universitarios de Mayores } \\
\text { y su contribución al aprendizaje a lo largo } \\
\text { de la vida }\end{array}$ & $\begin{array}{l}\text { Fernández-García, } \\
\text { A., García, J. L., y } \\
\text { Pérez, G. }\end{array}$ & $\begin{array}{l}\text { Nacional de } \\
\text { Educación a } \\
\text { distancia }\end{array}$ & Empírico & $\begin{array}{l}\text { Revista Complutense de } \\
\text { Educación }\end{array}$ \\
\hline
\end{tabular}




\begin{tabular}{|c|c|c|c|c|c|}
\hline 2014 & $\begin{array}{l}\text { Educación permanente: los programas uni- } \\
\text { versitarios para mayores como respuesta a } \\
\text { una nueva realidad social }\end{array}$ & Valle, J. E. & de Valencia & Empírico & $\begin{array}{l}\text { Revista de la educación } \\
\text { superior }\end{array}$ \\
\hline 2015 & $\begin{array}{l}\text { Nuevos perfiles de alumnos en las aulas de } \\
\text { mayores. Reflexiones en torno a sus percep- } \\
\text { ciones y expectativas. }\end{array}$ & $\begin{array}{l}\text { Argente del Casti- } \\
\text { llo, C. }\end{array}$ & Granada & Teórico & $\begin{array}{l}\text { XIV encuentro estatal } \\
\text { de Programas Univer- } \\
\text { sitarios para Mayores }\end{array}$ \\
\hline 2015 & $\begin{array}{l}\text { ¿Qué nuevas demandas educativas, investi- } \\
\text { gadoras y de servicio a la sociedad de los } \\
\text { alumnos mayores no están todavía incorpora- } \\
\text { das de manera generalizada en nuestra oferta } \\
\text { formativa? Propuesta de la Universidad de } \\
\text { Deusto: DeustoBide-Escuela de Ciudadanía }\end{array}$ & Lázaro, Y. & Deusto & Teórico & $\begin{array}{l}\text { XIV encuentro estatal } \\
\text { de Programas Univer- } \\
\text { sitarios para Mayores }\end{array}$ \\
\hline 2015 & $\begin{array}{l}\text { Algunas demandas educativas, investigado- } \\
\text { rasy de servicio a la sociedad para mejorar los } \\
\text { Programas Universitarios de Mayores (PUM) }\end{array}$ & Blázquez, F. & Extremadura & Teórico & $\begin{array}{l}\text { XIV encuentro estatal } \\
\text { de Programas Univer- } \\
\text { sitarios para Mayores }\end{array}$ \\
\hline 2017 & $\begin{array}{l}\text { Los PUMs en la formación de mayores como } \\
\text { activos sociales }\end{array}$ & Pérez, A. & Valencia & Teórico & $\begin{array}{l}\text { XV encuentro estatal de } \\
\text { Programas Universita- } \\
\text { rios para Mayores }\end{array}$ \\
\hline 2017 & $\begin{array}{l}\text { El voluntariado, impulso del envejecimiento } \\
\text { activo. El objeto de su motivación }\end{array}$ & Villegas, E. y Bru, C. & Alicante & Empírico & $\begin{array}{l}\text { XV encuentro estatal de } \\
\text { Programas Universita- } \\
\text { rios para Mayores }\end{array}$ \\
\hline
\end{tabular}

Fuente: Elaboración propia. 


\section{Discusión y conclusiones}

La proliferación de los PUM en España responde, tanto a los cambios socio-demográficos que ha experimentado nuestro país durante las últimas décadas, como al cambio en las funciones de las universidades (Valle, 2014), especialmente en la promoción de su función social (Lázaro y Aguilar, 2011). Por su parte Palmero (2013) añade a los motivos anteriores los avances científicos y la autopercepción de las personas mayores.

Tras la revisión de la literatura científica, hemos detectado determinados desafíos a los cuales los PUM se están enfrentando actualmente, pero que, si cabe, en los próximos se acrecentarán.

El primero de ellos está relacionado con el perfil del alumnado. Tal como señala Argente del Castillo (2015), en los últimos años se ha experimentado un rejuvenecimiento del alumnado que participa en los PUM, aumentando el intervalo de edad entre los cincuenta y sesenta y cinco años. Esto es el resultado, principalmente y tal como apuntaba la Junta de Andalucía (2010), al fenómeno de las prejubilaciones. En contraste a lo expuesto por Palmero (2013), donde identificaba el grueso del alumnado con quienes no tuvieron una oportunidad en su juventud, en la actualidad se identifica una tendencia con respecto al nivel educativo que presenta el alumnado, con un gran incremento de personas con titulación universitaria, las cuales presentan intereses más específicos y menos generalistas (Argente del Castillo, 2015). En este último sentido, Blázquez (2015) apunta a cómo desde 2001 a 2011 se ha duplicado la tasa de alumnado con estudios secundarios y universitarios, pasando de un $30 \%$ a un $60 \%$.

El segundo desafío al que se enfrentan los PUM es el cambio de rol que los adultos mayores están experimentando en la sociedad. Las personas mayores acceden cada vez más preparados a esta etapa lo que les permite, por una parte, tener mayores aspiraciones educativas, y por otra asumir mayores responsabilidades en la sociedad (Blázquez, 2015).

Estas nuevas demandas obligan a los PUM, además de su vertiente formativa, a adoptar la función de formar a agentes activos del cambio social (Lázaro y Aguilar, 2011; Lorente, 2013; Pérez, 2017) y para ello es necesario profundizar en aptitudes transformadoras más allá de habilidades sociales (Blázquez, 2015). Es en este punto donde entra en acción la necesidad de abordar los currículos de los PUM desde una estrategia de EpD, ya que no hemos localizado evidencias de que el diseño de los programas curriculares de los PUM esté basados en dicha estrategia. Sin embargo, podemos observar muchos de los principios de la EpD, 
tanto en los en currículos como en los procesos de enseñanza-aprendizaje desarrollados por los PUM.

Con respecto a la dimensión cognitiva, Ávila (2013), entre otros autores, señala la importancia de abordar los planes formativos de los PUM desde el respeto a los derechos fundamentales y la equidad, la igualdad de oportunidades, los valores democráticos y de paz, así como el compromiso ético.

Son muchos los autores y las autoras que hacen especial énfasis en los beneficios que la educación a lo largo de la vida ofertada por los Centros de Enseñanza Superior, reporta sobre el alumnado y la sociedad. Beltrán (2013) basándose en las investigaciones de Pastor y Peralta (2012), destaca la equidad y la cohesión social, el aumento de la longevidad y de la participación, el aumento de los valores de tolerancia y civismo, así como el descenso de la desigualdad. En el mismo sentido, Palmero (2013), apunta al aumento de la justicia social y de la democracia gracias a estos Programas.

En relación a la dimensión procedimental, Cabedo (2011) apunta a la importancia de incorporar metodologías más participativas, desde el paradigma de "aprender a aprender", para facilitar la adquisición de habilidades y destrezas, como necesidad de adaptación a los cambios sociales. Otros autores (Bru, 2011; Pérez, 2017) prefieren referirse a la adquisición de capacidades, requeridas para la transformación social, como cambio de modelo en contraste a la mera adquisición de conocimientos. En ambos casos, podemos identificar las teorías que conforman la base psicológica del modelo de EpD propuesto por Boni y Pérez (2006).

Con respecto a la dimensión actitudinal, diversos autores y autoras (Fernández et al., 2013; Lázaro y Aguilar, 2011; Lorente, 2013) ponen el acento en como muchas de las acciones formativas desarrolladas por los PUM tienen como objetivo la concienciación sobre la realidad actual, al tiempo que inciden sobre las mismas como agentes del cambio. Por su parte, Lázaro (2015) relaciona las propuestas educativas realizadas desde los PUM con las características del concepto de ciudadanía:

a) Dimensión personal, que implica la capacidad de reflexión, crítica y comportamiento hacia los aspectos más relevantes de la sociedad actual: medio ambiente, multiculturalidad, conflictividad...

b) Dimensión social, que permite interaccionar y trabajar con personas en diversos ambientes y contextos. 
c) Dimensión espacial, determinada por la implicación de los/as ciudadanos/as en la sociedad, en sus niveles local, nacional e internacional.

d) Dimensión temporal que implica una mirada hacia el pasado que permite crear la conciencia del impacto de nuestras actuaciones en el futuro sobre la ciudadanía (Lázaro, 2015, p. 537).

Por otra parte, en la revisión realizada por Villegas y Bru (2017), se identifica a las personas adultas mayores como un colectivo motivado a desarrollar acciones de voluntariado en el ámbito de la educación informal de los PUM. Motivación determinada principalmente por la importancia de ayudar a los demás, pero también como oportunidad de aprendizaje sobre el mundo que nos rodea. Las autoras también señalan el aumento de la autoestima al realizar este tipo de actividades.

Una vez analizadas las tres dimensiones, consideramos que hay que abordar una cuestión que crea controversia entre las fuentes consultadas. Nos estamos refiriendo a la necesidad o no de institucionalizar los PUM. A este asunto hay que otorgarle una gran importancia, ya que la institucionalización o no de los PUMs facilitará o no la incorporación de una estrategia de EpD en sus currículos. Ávila (2013) propone la organización de éstos en competencias (conocimientos, habilidades, actitudes, valores, emociones y motivaciones), que "...constituye un "saber hacer" que se aplica de manera reflexiva y no mecánica, debe adaptarse a la diversidad de los contextos y tiene un carácter integrador" (p. 179), muy en consonancia con el modelo de EpD tomado como referencia en el presente trabajo. De todos es sabida la dificultad de introducir enseñanzas en la formación reglada de valores relacionados con la $\mathrm{EpD}$.

Por otra parte, es imprescindible que la Universidad haga una apuesta clara por la educación de adultos mayores con el fin de otorgarle la entidad que merece y desterrar del imaginario colectivo que se trata de programas asistencialistas de carácter cultural y de tiempo libre y cuya única finalidad es entretener, para convertirlos en verdaderos semilleros de ciudadanos y ciudadanas adultas activamente comprometidos con la sociedad. Debemos referirnos a la educación de personas adultas más que como un derecho, como una consecuencia de una ciudadanía activa (Lázaro, 2015).

Desde la Universidad, como agente activo de cambio social, se están desarrollando acciones, desde sus tres vertientes: docente, investigadora y de extensión universitaria, encaminadas al desarrollo de una sociedad del conocimiento para todos y todas. Es necesario que la Universidad haga, si cabe, un mayor esfuerzo para adaptarse, tanto a las transformaciones socio-demográficas, tales como el aumento de la demanda de acciones formativas para las personas mayores causado 
por el BabyBoom comentado en el apartado de introducción, como a las nuevas exigencias derivadas del cambio del perfil del alumnado.

Sin embargo, consideramos que es necesario que la Universidad incida en la investigación de aquellos aspectos relacionados con la educación de adultos, ya que como hemos podido comprobar, existe poca literatura científica al respecto. Por otra parte, instamos a la comunidad científica especializada en EpD, centrada principalmente en la educación formal de primaria, secundaria y grado, y en la educación no formal desarrollada por otro tipo de organizaciones, a introducir el ALV en la Universidad como una de sus futuras líneas de investigación con el objetivo de dar respuesta a los cambios socio-demográficos descritos durante el presente trabajo.

Hemos podido constatar que los PUM integran muchos de los conceptos contenidos en las dimensiones cognitiva, procedimental y actitudinal de la EpD, pero consideramos que este hecho no es consecuencia del compromiso de estos programas en la integración de una clara estrategia de $\mathrm{EpD}$ en los mismos, sino el resultado de las buenas prácticas desarrolladas en ellos. Aprovechando la necesidad de reformulación de los currículos de los PUM, debido a diferentes factores señalados anteriormente, y planteada por diversos investigadores e investigadoras, consideramos que la introducción explícita de un modelo de EpD en los PUM contribuiría a abordar de manera más global la transformación de nuestras sociedades y otorgar a nuestras personas mayores un papel central en este proceso.

Por otra parte, también se ha puesto de manifiesto la gran motivación hacia el aprendizaje que presentan las personas mayores que participan en los PUMs, así como su predisposición al asociacionismo y voluntariado, lo que les convierte en excelentes transmisores/as de los principios que integran la EpD.

También se ha hecho patente que la formación de personas mayores en las próximas décadas, se enfrenta a nuevos retos, y que las universidades deberán ajustar la oferta formativa de los PUM para darles respuesta desde una perspectiva de $\mathrm{EpD}$, en consonancia con las exigencias de las agendas internacionales en materia educativa.

Por último, y tal como hemos señalado en el apartado de introducción, resaltar que nos encontramos ante la plataforma idónea para desarrollar acciones educativas relacionadas con la EpD en consonancia con las necesidades establecidas por los Organismos Internacionales. Ello a causa, principalmente, de la capacidad de los Centros de Educación Superior de crear alianzas con el resto de actores de la sociedad con el fin de desarrollar las cuatro estrategias descritas anteriormente: Sensibilización, Formación, Investigación e Incidencia Política y Movilización social. 


\section{Referencias}

Abellán, A., Ayala, A., Pérez, J. y Pujol, R. (2018) “Un perfil de las personas mayores en España 2018. Indicadores estadísticos básicos". Informes Envejecimiento en red, 17. Madrid.

AEPUM (2018, Marzo 3) Estadísticas por curso académico de los PUM. [Página web]. Disponible en https://www.aepumayores.org/es/contenido/ estad-sticas-por-curso-acad-mico.

Argente del CAstilLo, C. (2015) "Nuevos perfiles de alumnos en las aulas de mayores. Reflexiones en torno a sus percepciones y expectativas". En XIV encuentro estatal de Programas Universitarios para Mayores (pp. 561-569). Granada: Universidad de Granada.

Argibay, M., Celorio, G., y Celorio, J. J. (2009) Educación para la Ciudadanía Global: debates y desafíos. Bilbao: Hegoa.

ÁVILA, R. (2013) "El espacio europeo de educación superior (EEES), un ámbito de organización educativa en los diseños curriculares de los PUMS. Competencias básicas, curriculum integrado y aprendizaje cooperativo". En XIII encuentro estatal de Programas Universitarios para Mayores (pp. 168-180). Valencia: Universitat de València.

BAselga, P., FerRero, G. y Boni, A. (COORDS.) (2004) La Educación para el desarrollo en el ámbito formal, espacio común de la cooperación y la educación: propuestas para una estrategia de acción integrada. Valencia: Editorial Universitat Politècnica de València.

BetTRán, J. (2013) "Ser para aprender. Los beneficios sociales de la educación a lo largo de la vida". En XIII encuentro estatal de Programas Universitarios para Mayores (pp.1 10-123). Valencia: Universitat de València.

BLÁZQUEZ, F. (2015) "Algunas demandas educativas, investigadoras y de servicio a la sociedad para mejorar los Programas Universitarios de Mayores (PUM)". En XIV encuentro estatal de Programas Universitarios para Mayores (pp. 543-558). Granada: Universidad de Granada.

BoNI, A. (2005) La Educación para el Desarrollo en la enseñanza universitaria como una estrategia de la cooperación orientada al desarrollo humano. (Tesis Doctoral). Valencia: Universidad de Valencia. 
BONI, A. y LEÓN, R. (2013) "Educación para una ciudadanía global: una estrategia imprescindible para la justicia social". En Déborah Itriago (Eds.), La realidad de la ayuda 2012. Una evaluación independiente de la ayuda y las políticas de desarrollo en tiempos de crisis (pp. 214-239). Intermon Oxfam.

BONI, A. y Pérez, A. (2006) Construir la ciudadanía global desde la universidad. Barcelona: Intermón Oxfam.

Boni, A., Calabouig, C. y Pérez, A. (COORDS.) (2014) Universidad y cooperación al desarrollo. Contribuciones de las universidades al Desarrollo Humano. Valencia: Editorial Universitat Politècnica de València.

BONI, A., López, E. y BARAHONA, R. (2013) "Approaching quality of global education practices through action research: A non-governmental development organization-university collaborative experience". International Journal of Development Education and Global Learning 5(2), 31-46.

BRU, C. (201 1) "Buenas prácticas en los Programas Universitarios para Mayores. Origen y estado de la cuestión en España". En IV Congreso Iberoamericano de universidades para mayores (pp. 417-433). Alicante: Asociación Estatal de Programas Universitarios para Mayores.

CABEDO, A. (2010) La educación permanente: La Universidad y las personas mayores. Castelló de la Plana: Publicaciones de la Universitat Jaume I.

CABEDO, S. (2011) "La Universidad y la globalización del conocimiento: movilidad, intercambio, cooperación nacional y relaciones internacionales". En IV Congreso Iberoamericano de universidades para mayores. (pp. 1.019-1.032). Alicante: Asociación Estatal de Programas Universitarios para Mayores.

Celorio, G. (2013) "Sensibilización y Educación para el Desarrollo". En R. Agost, A. M. Fuertes, I. Giménez y G. Soto (Eds.), Cooperación descentralizada pública. Introducción, enfoques y ámbitos de actuación (pp. 225-261). Castelló de la Plana: Publicacions de la Universitat Jaume I.

- (2014) "A modo de síntesis. Aportaciones al debate sobre una educación emancipadora". En Cambiar la educación para el cambiar el mundo... ¡Por una acción educativa emancipadora! (pp. 215-226). Bilbao: Hegoa.

CEURI (2000) Estrategia de cooperación universitaria al desarrollo. Córdoba: CEURI.

Consejo Unión Europea (2002) Resolución del Consejo de 27 de junio de 2002 
sobre la educación permanente. Disponible en: https://goo.gl/smrMdH.

DeloRs, J. (1996) Informe Delors. La educación encierra un tesoro. Madrid: Unesco-Santillana.

EsCUDER, P. (2017) Educación para la Inclusión Digital en Personas Mayores. (Tesis doctoral). Universitat Jaume I, Castellón.

Fernández, M. I. Arnay, J. y Marrero, J. (2013) "El envejecimiento constructivo: el papel de la Educación Superior". En XIII encuentro estatal de Programas Universitarios para Mayores (pp. 221-232). Valencia: Universitat de València.

GIL, A., OCHOA, L. y NowACKA, U. (2014) "Models". En P. Escuder-Mollón, y S. Cabedo (Eds.), Education and quality of life of senior citizens (pp. 105-140). Castellón de la Plana: Publicaciones de la Universitat Jaume I.

IMSERSO (2011) Envejecimiento activo. Libro blanco. Madrid: IMSERSO.

Junta de Andalucía (2010) Libro Blanco de Envejecimiento Activo. Sevilla: Junta de Andalucía.

LÁZARO, Y. (2015) "¿Qué nuevas demandas educativas, investigadoras y de servicio a la sociedad de los alumnos mayores no están todavía incorporadas de manera generalizada en nuestra oferta formativa?" Propuesta de la Universidad de Deusto: DeustoBide-Escuela de Ciudadanía. En XIV encuentro estatal de Programas Universitarios para Mayores (pp. 533-541). Granada: Universidad de Granada.

LÁZARO, Y. y AgUILAR, E. (2011) "Un ejemplo de innovación universitaria: las experiencias de ocio formativas de los programas de adultos de la Universidad de Deusto". En IV Congreso Iberoamericano de universidades para mayores (pp. 91-104). Alicante: Asociación Estatal de Programas Universitarios para Mayores.

LemieuX, A. (1997) Los Programas Universitarios para Mayores. Enseñanza e Investigación. Madrid: IMSERSO.

LORENTE, X. (2013) "Hacia una perspectiva europea de la formación continua en mayores". En XIII encuentro estatal de Programas Universitarios para Mayores (pp.41-51). Valencia: Universitat de València.

LoZANO, J. (2009) ¿¿Qué educación para qué desarrollo? Pistas de reflexión para la sexta generación de Educación para el Desarrollo. (Tesis de máster sin publicar). Sevilla: Universidad Pablo de Olavide. 
Martorell, I., Medrano, M., Solé, C., Vila, N., Y Cabeza, L. F. (2009) "Inquiry-based learning for older people at a university in Spain". Educational Gerontology, $35(8), 712-731$.

OMS (2002) Active Ageing: a Policy Framework. Ginebra: Organización Mundial de la Salud.

ONU (2000) Declaración del Milenio. Disponible en: https://undocs.org/es/A/ $\mathrm{RES} / 55 / 2$.

- (2015a) Transformar nuestro mundo: la Agenda 2030 para el DesarroIlo Sostenible. Disponible en: http://www.un.org/ga/search/view_doc. asp? symbol=A/70/L.1\&Lang=S.

- (2015b) Objetivos de Desarrollo del Milenio. Informe de 2015. Disponible en: http://www.un.org/es/millenniumgoals/pdf/2015/mdg-report-2015_spanish.pdf.

- (2017) World Population Prospetcs. The 2017 Revision. Key findings \& avance tables. Nueva York: Naciones Unidas.

ORTEGA, M. L. (2007) Estrategia de Educación para el Desarrollo de la cooperación española. Madrid: Ministerio de Asuntos Exteriores y de Cooperación.

Palmero, C. (2013) "Impacto de los programas universitarios para mayores en la universidad y en la sociedad". En XIII encuentro estatal de Programas Universitarios para Mayores (pp. 139-151). Valencia: Universitat de València.

PAstor, J. M., y PerAlta, C. (2012) La contribución socioeconómica del sistema universitario español. Madrid: Ministerio de Educación.

Pérez, A. (2017) "Los PUMs en la formación de mayores como activos sociales". En XV encuentro estatal de Programas Universitarios para Mayores (pp. 22-32). Santiago de Compostela: Noreste Gráfico Impresor S.L.

PNUD (1990) Desarrollo humano. Informe 1990. Bogotá. Tercer Mundo Editores-PNUD.

PRISMA (2018, Enero, 13) Preferred Reporting Items for Systematic Reviews and Meta-Analyses. [Página web]. Disponible en: http://prisma-statement.org/.

Subires, M. y Delgado, J. (2017) "Competencias digitales en los Programas Universitarios de Mayores (PUM) de las Universidades Españolas". En XV encuentro 
estatal de Programas Universitarios para Mayores (pp. 136-150). Santiago de Compostela: Noreste Gráfico Impresor S.L.

UNESCO (2000) Marco de Acción de Dakar. Educando para todos. París: UNESCO.

- (2010a) Informe mundial sobre el aprendizaje y la educación de adultos. Hamburgo: UNESCO Institute for Lifelong Learning.

- (2010b) Marco de acción de Belém. Aprovechar el poder y el potencial del aprendizaje y la educación de adultos para un futuro viable. Hamburgo: UNESCO Institute for Lifelong Learning.

- (2014) Declaración final de la Reunión Mundial sobre la EPT de 2014. El Acuerdo de Mascate. Disponible en: http://www.unesco.org/new/fileadmin/ MULTIMEDIA/FIELD/Santiago/pdf/Muscat-Agreement-ESP.pdf.

- (2015) Declaración de Incheon. Educación 2030: Hacia una educación inclusiva y equitativa de calidad y un aprendizaje a lo largo de la vida para todos. Disponible en: http://unesdoc.unesco.org/images/0024/002456/245656s.pdf.

- (2016a) Desglosar el Objetivo de Desarrollo Sostenible 4: Educación 2030, guía. Disponible en: http://unesdoc.unesco.org/images/0024/002463/246300S.pdf.

- (2016b) Recomendación sobre el aprendizaje y la educación de adultos. Disponible en: http://unesdoc.unesco.org/images/0024/002451/245119M. pdf\#page=3.

VAlLE, J. E. (2014) "Educación permanente: los programas universitarios para mayores en España como respuesta a una nueva realidad social". Revista de la educación superior, 43(171), 117-138.

VILLEGAS, E. y BRU, C. (2017) "El voluntariado, impulso del envejecimiento activo. El objeto de su motivación". En XV encuentro estatal de Programas Universitarios para Mayores (pp.218-233). Santiago de Compostela: Noreste Gráfico Impresor S.L. 